\title{
Putting to rest the myth of creatine supplementation leading to muscle cramps and dehydration
}

\author{
V J Dalbo, ${ }^{1}$ M D Roberts, ${ }^{1}$ J R Stout, ${ }^{2}$ C M Kerksick ${ }^{1}$
}

${ }^{1}$ Applied Biochemistry and Molecular Physiology Laboratory, Department of Health and Exercise Science, University of Oklahoma, Norman, Oklahoma, USA; ${ }^{2}$ Metabolic and Body Composition Laboratory, Department of Health and Exercise Science, University of Oklahoma, Norman, Oklahoma, USA

Correspondence to: Vincent J Dalbo, MS, Department of Health and Exercise Science, University of Oklahoma, 1401 Asp Avenue, Norman, OK 73019, USA: vinnyjames@ou.edu

Accepted 3 November 2007 Published Online First

9 January 2008

\section{ABSTRACT}

Creatine is one of the most popular athletic supplements with sales surpassing 400 million dollars in 2004. Due to the popularity and efficacy of creatine supplementation over 200 studies have examined the effects of creatine on athletic performance. Despite the abundance of research suggesting the effectiveness and safety of creatine, a fallacy appears to exist among the general public, driven by media claims and anecdotal reports, that creatine supplementation can result in muscle cramps and dehydration. Although a number of published studies have refuted these claims, a recent position statement by the American College of Sports Medicine (ACSM) in 2000 advised individuals who are managing their weight and exercising intensely or in hot environments to avoid creatine supplementation. Recent reports now suggest that creatine may enhance performance in hot and/or humid conditions by maintaining haematocrit, aiding thermoregulation and reducing exercising heart rate and sweat rate. Creatine may also positively influence plasma volume during the onset of dehydration. Considering these new published findings, little evidence exists that creatine supplementation in the heat presents additional risk, and this should be taken into consideration as position statements and other related documents are published.

In 1835 creatine was discovered as a component of meat ${ }^{1}$ and by 1847 animal studies confirmed the presence of creatine in skeletal muscle. However, it was not until 1927 and the discovery of phosphocreatine in feline muscle that researchers began to understand the importance of creatine in skeletal muscle bioenergetics. ${ }^{2}$ A human study involving creatine supplementation conducted in 1967 found creatine to be involved with ATP synthesis in muscle. ${ }^{3}$ Further research in the 1970s found creatine to positively influence the growth of rats and chicken embryos, ${ }^{4}$ while in 1981 human subjects consuming creatine to treat gyrate atrophy (a disease resulting in the constriction of visual fields) reported an increase in strength. ${ }^{5}$ Over 10 years later in 1992, creatine supplementation was found to significantly increase skeletal muscle creatine concentrations in humans. ${ }^{6}$ Since 1993, over 200 studies have been published examining the effects of creatine supplementation on athletic performance $^{7}$ and a 2000 position statement by the ACSM suggested creatine was effective at enhancing high-intensity, short-duration exercise, especially repeated bouts. ${ }^{8}$

The popularity of creatine grew rapidly when The Times reported that $100 \mathrm{~m}$ sprint champion, Linford Christie, consumed creatine prior to the 1992 Olympics. ${ }^{9}$ Creatine's popularity exploded with sales nearing 100 million dollars in $1998^{10}$ and exceeding 400 million dollars by $2004 .{ }^{11}$ For these reasons, much research has been conducted on the safety of creatine supplementation ${ }^{92-19}$ but a fallacy exists, which has likely been driven by the media $^{17}$ and anecdotal reports, ${ }^{20-25}$ that creatine causes muscle cramps and dehydration. Further, the implementation of The Dietary Supplements and Health Education Act (DSHEA) in 1994 may have magnified concerns regarding creatine's safety. ${ }^{26}$ Media pressure regarding the safety of creatine began in 1998 when The Lancet published a case report of a 25-year-old man with focal segmental glomerulosclerosis and frequently relapsing steroid-responsive nephritic syndrome who experienced deterioration in renal function. Creatine use was discontinued upon his physician's order, and this resulted in restoration of normal kidney function. Results from this case report provided evidence that creatine supplementation may have been related to renal dysfunction. ${ }^{27}$

Within 3 days following the release of this publication a French newspaper L'Equipe reported that creatine supplementation can impair kidney function, ${ }^{9}$ even though previous studies found creatine supplementation to have no effect on markers of renal stress. ${ }^{16}{ }^{28-30}$ Despite the apparent safety of creatine the United States media began to report on the dangers of creatine supplementation, focusing on dehydration and muscle cramping. Shortly thereafter the ACSM recommended that individuals who are managing their weight and exercising intensely or in hot environments should avoid the use of creatine supplementation. ${ }^{8}$ The physiological rationale suggesting that creatine use may cause dehydration and cramping is based on the premise that creatine is an osmotically active substance that drives water into cells. Specifically, the first week of creatine supplementation at a dose of $20 \mathrm{~g} / \mathrm{d}$ for $5 \mathrm{~d}$ tends to result in a $1-3 \mathrm{~kg}$ increase in body mass attributable to an increase in total body water. ${ }^{31}$ Some researchers theorised that creatine supplementation could result in a fluid balance shift where more water could be retained intracellularly ${ }^{32}$ and the bound intracellular water (ICW) might not be released into the extracellular compartment for thermoregulation, which could lead to cramping, dehydration, altered electrolyte balance and other heat-related problems. ${ }^{33}$

Scientific evidence supporting these claims is nonexistent, as no peer-reviewed published papers have provided evidence to substantiate the aforementioned claims. ${ }^{31}$ The only studies found to report the occurrence of dehydration and/or muscle cramping from creatine supplementation have been anecdotal reports $^{212324}$ or speculations that creatine use may result in a fluid balance shift causing increases in 
intracellular fluid which could alter electrolyte balance ${ }^{120} 34$ or be unavailable for thermoregulation. ${ }^{1}{ }^{20} 32$

\section{ANECDOTAL EVIDENCE}

Several self-report studies have examined potential negative effects of creatine supplementation in athletes. ${ }^{21} 2324$ The first consisted of 219 collegiate athletes, of whom 90 (41\%) athletes reported creatine use with 34 (38\%) reporting negative effects including gastrointestinal distress and muscle cramping $(24 \%$ and $27 \%$, respectively) ${ }^{21}$ Another study consisted of 1349 high school football players, of whom 418 athletes reported creatine use. Of these, a total of 71 participants (16.9\%) reported negative effects including dehydration, muscle cramps, diarrhoea and upset stomach. ${ }^{24}$ The last study was composed of 52 male collegiate athletes (28 football and 24 baseball players) who consumed creatine. In these individuals, 16 reported diarrhoea, 13 muscle cramps, two muscle strains or tears, seven undesired weight gain and seven dehydration, while 12 and 14 participants, respectively, reported other effects and no effects. Despite the reported negative effects, 40 athletes (77\%) planned on continuing creatine use, while 39 participants exceeded the recommended maintenance dose of 2 to $5 \mathrm{~g} / \mathrm{d}$ and 18 participants consumed 17 to $20 \mathrm{~g} / \mathrm{d}$ as a maintenance dose. ${ }^{23}$ It must be noted that participants in each study were athletes, particularly football players who were practising in hot environments, which are known to promote muscle cramps. Additionally, none of the studies controlled for use of other supplements and/or the dose of creatine consumed. In fact, Greenwood et $a l^{21}$ noted that $43 \%$ of participants were consuming supplements in addition to creatine and $91 \%$ of participants who reported negative effects exceeded the recommended maintenance dose of $5 \mathrm{~g}$ per day.

In 2003 Greenwood et a ${ }^{22}$ conducted a study suggesting that creatine supplementation may reduce the risk of muscle cramps and/or dehydration by monitoring injury rates of 72 NCAA Division 1A football players over a period of 4 months. Participants chose to consume creatine $(n=38)$ or not consume creatine $(n=34)$. Participants in the creatine group consumed a loading phase of $0.3 \mathrm{~g} / \mathrm{kg}$ for 5 days followed by a maintenance phase of $0.03 \mathrm{~g} / \mathrm{kg}$ for 115 days. Participants in the creatine group were found to have significantly less muscle cramping, muscle tightness, muscle strains, heat illness or dehydration and fewer total injuries than participants who chose not to consume creatine.

\section{FLUID VOLUME STUDIES}

The first known study to report relative changes in fluid volume during creatine supplementation was conducted in $1998 .{ }^{35}$ The testing protocol required 10 aerobically trained men to consume $0.07 \mathrm{~g}$ creatine per $\mathrm{kg}$ fat-free mass every $3 \mathrm{~h}$ for 3 days. Multifrequency bioimpedance (MBIA) was used to estimate total body water (TBW) and extracellular water (ECW) before, during and after creatine supplementation. Data analysis found creatine supplementation to increase TBW and intracellular water (ICW) while having no effect on ECW, leading researchers to conclude that creatine supplementation can lead to a fluid balance shift. However, the authors did not access muscle creatine content, so it is unknown whether changes in fluid distribution were due to increased muscle creatine concentrations.

\section{CREATINE SUPPLEMENTATION IN CONTROLLED HOT AND/OR HUMID CONDITIONS}

There have been several controlled studies which directly examined the effects of creatine supplementation on muscle cramping and dehydration in hot and/or humid conditions. ${ }^{22} 25333637$ One of the first studies to examine the effects of creatine in conditions likely to promote dehydration was conducted in $2000 .^{38}$ Participants were required to complete two exercise sessions. During the first session participants completed five $5 \mathrm{sec}$ maximal sprints on a cycle ergometer against a resistance of $0.090 \mathrm{~kg} / \mathrm{kg}$ body mass in a thermally controlled room maintained at $\sim 32^{\circ} \mathrm{C}$ and $50 \%$ relative humidity $(\mathrm{RH})$. Upon completion of the first testing session participants were randomly assigned to consume $20 \mathrm{~g} / \mathrm{d}$ in four $5 \mathrm{~g}$ doses dissolved in $250 \mathrm{ml}$ of warm water or to a control group which consumed only water. During the second session participants completed five $5 \mathrm{sec}$ maximal sprints followed by a $75 \mathrm{~min}$ moderate-intensity, intermittent exercise protocol designed to promote fluid loss. Participants again completed five $5 \mathrm{sec}$ maximal sprints followed by another 75 min moderate-intensity, intermittent exercise protocol. Creatine supplementation did not enhance performance as no significant differences were found between groups for any measure of relative peak power or relative total work. However, there were no differences between groups regarding loss of body mass or per cent change in plasma volume following each of the $75 \mathrm{~min}$ fluid loss exercise protocols, suggesting that creatine supplementation in heat does not promote dehydration. Furthermore, creatine loading was found to result in a larger non-significant increase in per cent change of plasma volume than the consumption of water alone $(6.6 \%$ (SD $2.7 \%$ ) vs $1.3 \%$ (SD $2.2 \%)$, ${ }^{38}$ which could reduce the risk of cramping and dehydration in heat.

In 2001 Kern et al ${ }^{6}$ examined the effects of creatine supplementation on body composition, TBW and haematocrit by randomly assigning in a double-blind fashion 10 individuals to consume creatine while 10 others consumed a placebo. During the loading phase participants consumed $5.25 \mathrm{~g}$ four times daily for $5 \mathrm{~d}$ and $2 \mathrm{~g} / \mathrm{d}$ for the remaining $28 \mathrm{~d}$ while participants in the placebo group consumed an equivalent amount of sugar. Participants were tested before and after supplementation, first by having their $\mathrm{VO}_{2 \max }$ assessed before cycling at $60 \%$ of their maximum in an environmental chamber at $37^{\circ} \mathrm{C}$ and $25 \% \mathrm{RH}$. Both groups experienced an increase in TBW with the increase in TBW being significantly greater in the creatine group than the placebo group. There were no significant within-group differences in haematocrit resulting from supplementation, but the placebo group did have greater pre and post-supplementation haematocrit values. Additionally, post-supplementation body temperature in the creatine group was $0.37^{\circ} \mathrm{C}$ lower than pre-supplementation values. Furthermore, the creatine group presented a body temperature that was $0.20^{\circ} \mathrm{C}$ lower than the placebo group, with this and the aforementioned findings being statistically significant $(p<0.05)$. Thus, the inverse relationship between core temperature values and the accretion of body water during creatine supplementation provides additional support for the use of creatine in hot/ humid environments.

In 2004 Kilduff et al ${ }^{39}$ conducted a similar study examining creatine supplementation on thermoregulatory responses during exercise to exhaustion in 21 endurance-trained men. After being matched for body mass, participants exercised at 63\% (SD 5\%) of $\mathrm{VO}_{2 \max }$ in a hot environment $\left(30.3(\mathrm{SD} 0.5)^{\circ} \mathrm{C}\right)$ while being randomly assigned in a double-blind fashion to either a group consuming $22.8 \mathrm{~g} / \mathrm{d}$ of creatine for 7 days or a placebo group who consumed an equivalent amount of a glucose polymer. In a crossover fashion, participants were then retested using the same protocol. Using BIA creatine supplementation increased TBW and ICW without significantly increasing 


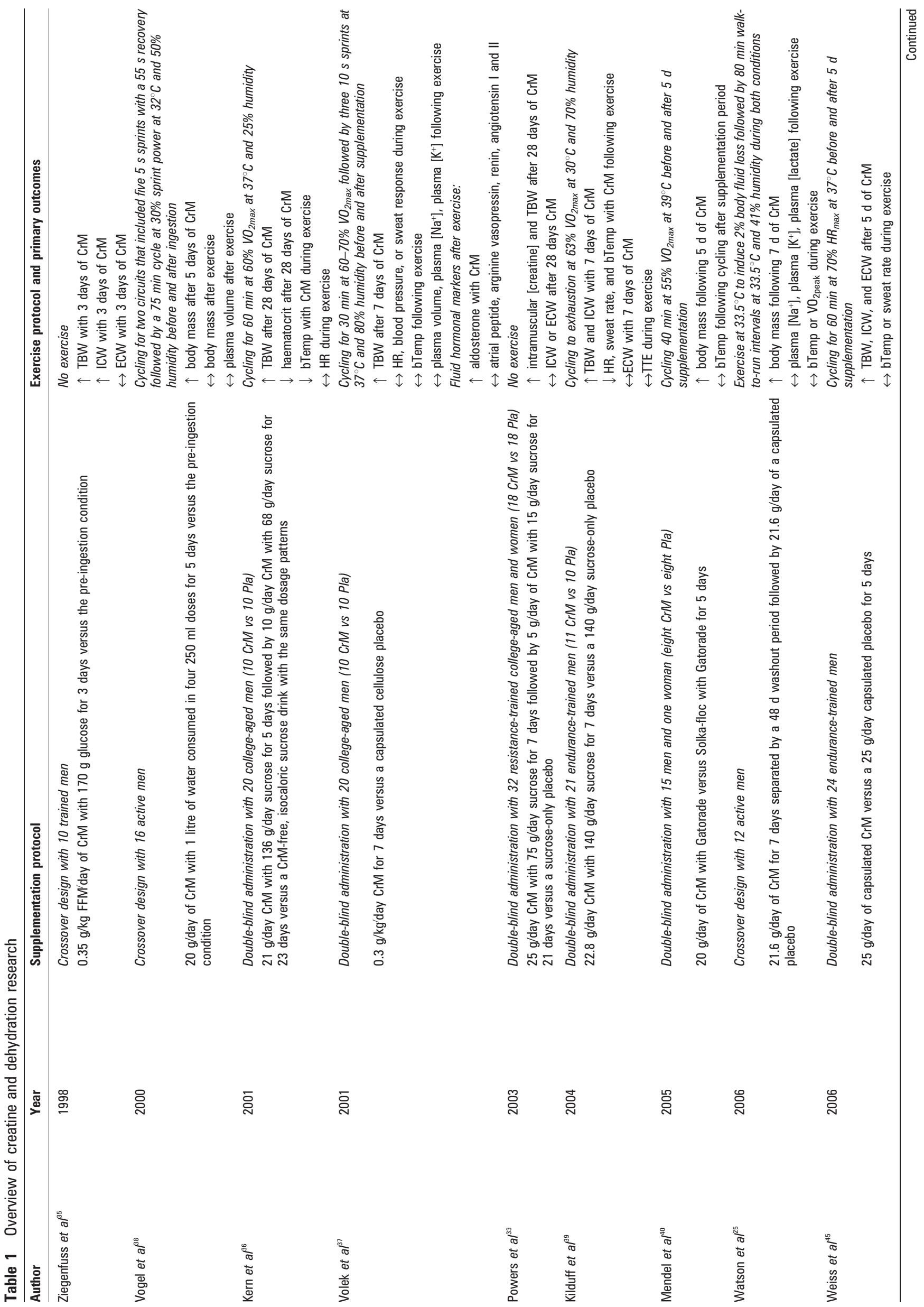


ECW, supporting the finding by Ziegenfuss et al ${ }^{35}$ that creatine supplementation may result in more fluid being stored in intracellular compartments. However, participants in the creatine group had a decreased heart rate, rectal temperature and sweat rate compared with the placebo group during exercise. Additionally, while creatine did not significantly improve time to exhaustion as a whole, participants identified as responders to creatine supplementation $(>20 \mathrm{mmol} / \mathrm{kg}$ increase in intramuscular creatine) significantly improved their endurance performance.

Another study conducted in 2005 had participants complete two separate heat-stressed trials after determination of $\mathrm{VO}_{2 \max }$ on a cycle ergometer. Following $\mathrm{VO}_{2 \max }$ determination, participants performed their first heat stress test, which consisted of cycling for $40 \mathrm{~min}$ at $55 \%$ of $\mathrm{VO}_{2 \max }$ in a thermally controlled room maintained at $39^{\circ} \mathrm{C}$. Participants were then randomly assigned in a double-blind fashion to consume $20 \mathrm{~g} / \mathrm{d}$ of either creatine with Gatorade or a placebo (cellulose) with Gatorade for $5 \mathrm{~d}$ and underwent a second heat stress test. Creatine supplementation was not found to hinder thermoregulation as there were no significant differences between groups in rectal or skin temperature. ${ }^{40}$

One of the first studies to examine the effects of creatine supplementation on resting and exercise-induced water regulation was conducted by Volek et al. ${ }^{37}$ The authors matched 20 men and instructed them to consume in double-blind fashion creatine at a dosage of $0.3 \mathrm{~g} / \mathrm{kg}$ of body weight five times daily or an equivalent amount of a cellulose placebo for $7 \mathrm{~d}$. Before and after supplementation both groups cycled for $30 \mathrm{~min}$ at 60 $70 \%$ of $\mathrm{VO}_{2 \text { peak }}$ before completing three $10 \mathrm{sec}$ sprints in an environmental chamber at $37^{\circ} \mathrm{C}$ and $80 \% \mathrm{RH}$. Body water was assessed using BIA and increases in TBW were found to occur in proportion to increases in total body mass, leading the authors to conclude that per cent body water remained unchanged after creatine supplementation. No significant differences $(p>0.05)$ were found between groups during exercise for heart rate, blood pressure, mean arterial pressure, ratings of perceived exertion, sweat response or body temperature. Moreover, plasma volume decreased in both groups during exercise, suggesting that creatine had no effect on fluid movement out of the plasma. Additionally, no significant differences were found between groups in electrolytes $\left(\mathrm{Na}^{+}, \mathrm{K}^{+}\right)$or in the water-regulatory hormones (eg, atrial peptide, arginine vasopressin, renin, angiotensin I and II). Aldosterone levels were significantly higher in the creatine group, but within normal levels for individuals exercising in hot environmental conditions. ${ }^{37}{ }^{41} 42$ The increased aldosterone response in the creatine group may also be explained by the increased exercise intensity, as peak power was significantly higher during each repeated sprint bout in the creatine group and small increases in exercise intensity have been found to elicit increased aldosterone responses. ${ }^{37}{ }^{43}$ In summary, this study and others consistently suggest that creatine supplementation can improve performance in hot environmental conditions without increasing the risk of muscle cramps and/or dehydration.

\section{DIRECT ASSESSMENT OF CREATINE SUPPLEMENTATION AND FLUID DISTRIBUTION}

Volek's study ${ }^{37}$ incited a subsequent study conducted by Powers et $a l,{ }^{33}$ which was one of the first studies to directly measure intramuscular creatine levels as well as fluid balance during creatine supplementation. Participants included 16 men and 16 women (menstrual cycle days 1-7), who were randomly assigned in a double-blind fashion to a creatine or a placebo 
group. Participants were tested on three occasions: before supplementation, after $7 \mathrm{~d}$ of supplementation at a dose of $5 \mathrm{~g} / \mathrm{d}$ of creatine or placebo five times daily, and after $28 \mathrm{~d}$ of supplementing at a dose of $5 \mathrm{~g} / \mathrm{d}$. Intramuscular creatine concentrations were assessed using spectrophotometric analysis of muscle biopsies extracted from the vastus lateralis muscle from the non-dominant leg of each participant, and body mass was assessed using a digital scale from the BOD POD. TBW was estimated using a deuterium oxide dilution method (via mass spectrometry) from venous blood samples. Additionally, ECW was estimated using a sodium bromide dilution method from venous blood samples (via high-performance liquid chromatography) and ICW was estimated by subtracting ECW from TBW. The creatine group had significantly higher muscle creatine concentrations than the placebo group after days 7 and 28. The creatine group also significantly increased body mass from day 1 to day 28, but not from day 1 to day 7 , suggesting that increases in body mass may be due to increased protein synthesis and not solely water retention. Both groups significantly increased TBW after days 7 and 28 with the creatine group experiencing significantly greater increases in TBW after both days than the placebo group. This study demonstrated that increases in muscle creatine concentration are associated with increased water retention and that increases in TBW during creatine supplementation appear to be equally distributed between ICW and ECW compartments.

\section{EFFECTS OF CREATINE SUPPLEMENTATION DURING EXERCISE IN DEHYDRATED INDIVIDUALS}

Watson et $a^{25}$ were among the first to examine the effects of creatine supplementation on heat tolerance in 12 dehydrated men using a double-blind, placebo-controlled, cross-over design. During the first trial participants in the experimental group consumed $21.6 \mathrm{~g} / \mathrm{d}$ of creatine for $9 \mathrm{~d}$ while participants in the placebo group consumed an equal amount of an undisclosed placebo. Following a 48 (SD 10) day washout period participants crossed-over to the other trial. On day 7 of each treatment participants performed an exercise tolerance test in an environmental chamber at $33.5(\mathrm{SD} 0.5)^{\circ} \mathrm{C}$ and $41 \%$ (SD 12\%) RH. The dehydration protocol consisted of participants standing (20 min), walking (30 min) and cycling (30 min) with the goal of dehydrating participants by $2.0 \%$ of body mass. Following the dehydration protocol participants exercised for $80 \mathrm{~min}$, consisting of four $20 \mathrm{~min}$ sequences comprising $4 \mathrm{~min}$ of standing, $13 \mathrm{~min}$ of walking and $3 \mathrm{~min}$ of sprinting. Consistent with prior research, body mass significantly increased during creatine supplementation. ${ }^{8} 31337$ The creatine $^{2}$ group was better able to maintain plasma volume during the first 20 minutes of the dehydration phase, but there were no differences in dehydration level or $\mathrm{Na}^{+}$and $\mathrm{K}^{+}$levels between groups. Moreover, no differences were found between groups for $\mathrm{VO}_{2 \text { peak, }}$ plasma lactate, respiratory exchange ratio, body temperature or physiological strain index. Results from this study suggest that creatine does not promote muscle cramps or dehydration even during a dehydrated state.

\section{EFFECT OF CREATINE SUPPLEMENTATION ON THERMOREGULATORY RESPONSES BETWEEN GENDERS}

The only study found to specifically examine gender differences in thermoregulation during creatine supplementation was conducted in 2004. Male $(n=10)$ and female $(n=10)$ participants completed a cycle ergometry test to obtain a measure of $\mathrm{VO}_{2 \text { peak }}$ to standardise the exercise intensity for the following two exercise sessions. Five days following the initial $\mathrm{VO}_{2 \text { peak }}$ cycle ergometry test participants completed a 30 min exercise session which consisted of cycling at $70-75 \%$ of $\mathrm{VO}_{2 \text { peak }}$ in a thermally controlled room $(24.04 \text { (SD } 1.63)^{\circ} \mathrm{C}$, $33.28 \%$ (SD 17.21\%) RH) before and following $7 \mathrm{~d}$ of creatine supplementation at a dose of $20 \mathrm{~g} / \mathrm{d}$. There were no significant differences between genders in rectal temperature, skin temperature or heart rate, leading the authors to conclude that creatine supplementation did not adversely affect thermoregulation in men or women. ${ }^{44}$

\section{RECENT WORK}

A recent study examining the effects of creatine supplementation on the thermoregulatory response during exercise in heat also suggests that creatine supplementation results in no adverse side-effects. ${ }^{45}$ The study consisted of 24 aerobically trained male athletes who completed two exercise sessions, cycling at $70 \%$ maximal heart rate in a temperature-controlled room $\left(37^{\circ} \mathrm{C}\right)$. Prior to and every $10 \mathrm{~min}$ during exercise, body water was assessed using a multi-frequency bioelectrical impedance spectroscopy device. Following the first session participants were placed in a creatine or placebo group in a counterbalanced double-blind fashion. Following a 5 day supplementation period and a 1 day recovery period, participants returned to the lab to perform the same test under identical conditions. The creatine group experienced significant increases in intracellular, extracellular and total body water volumes while no significant differences were found in core temperature or sweat loss in either group following supplementation. ${ }^{45}$

A more recent study (2007) utilising a double-blind crossover design examined the performance and thermoregulatory effects of creatine supplementation in seven competitive male cyclists and triathletes. Participants completed three $1 \mathrm{~h}$ cycling sessions at approximately $66 \%$ of their $\mathrm{VO}_{2 \max }$ in a thermally controlled room at a temperature of $37(\mathrm{SD} 1.0)^{\circ} \mathrm{C}$ and $\mathrm{RH}$ of $33 \%$ (SD $4 \%$ ). Following an initial $\mathrm{VO}_{2 \max }$ test to set the workload for the remaining three sessions, participants returned to the laboratory following a 5-7 day recovery period for baseline testing. Following baseline testing participants were randomly assigned in a double-blind counterbalanced crossover manner to consume either $20 \mathrm{~g} / \mathrm{d}$ of creatine or a placebo for 5 days prior to the second session. Following a minimum 28 day washout period participants consumed the other supplement and performed a third cycling trial. Creatine supplementation did not adversely affect any markers of thermal stress compared with baseline or the placebo condition as there were no significant differences between groups in body temperature; heart rate; systolic blood pressure; ratings of perceived exertion; or lactate, cortisol or aldosterone concentrations. In fact, plasma volume was maintained at a significantly higher level when participants were consuming creatine compared with baseline and placebo conditions. ${ }^{46}$ Results from this study suggest that creatine supplementation may aid the thermoregulatory response to exercise in heat by maintaining plasma volume.

Easton et al (2007) examined the combined effects of creatine and glycerol supplementation in response to exercise in heat $\left(30^{\circ} \mathrm{C}\right.$ and $\left.70 \% \mathrm{RH}\right)$. Participants were randomly assigned to consume $11.4 \mathrm{~g}$ of creatine or placebo (glucose) twice daily for two supplement regimes. During the first regime participants consumed their assigned supplement plus $1 \mathrm{~g}$ of glycerol per $\mathrm{kg}$ body mass twice daily or an additional placebo, creating four possible groups: placebo/placebo, placebo/glycerol, creatine/ placebo, and creatine/glycerol with exercise trials being 


\section{What is already known on this topic}

Creatine supplementation is known to increase intramuscular creatine and phosphocreatine stores, increasing the buffering capacity of the phosphagen system. This increased buffering capacity has been ultimately responsible for enhancing the ergogenic potential at various exercise intensities and workloads. Creatine is also known to be an osmotically active substance which draws water into cells. When mainstream use of creatine increased, some researchers theorised that creatine could result in a fluid balance shift where more water could be retained intracellularly and therefore be unavailable for thermoregulation. Subsequent research has found creatine supplementation to be safe, but the fallacy that creatine use can increase the risk of muscle cramps and dehydration still exists.

\section{What this study adds}

This study clearly highlights those studies which have examined the safety and efficacy of creatine supplementation in hot and/or humid conditions and other conditions which may challenge effective thermoregulation. Collectively, results from these studies suggest that creatine supplementation may decrease the risk of dehydration during exercise.

conducted pre and post-supplementation. Even though creatine supplementation did not enhance performance, participants consuming creatine did have a lower heart rate, body temperature and ratings of perceived exertion. The primary contribution of this study was the finding that glycerol consumption in conjunction with creatine led to a significantly greater increase in TBW than creatine alone, suggesting that the thermoregulatory properties of creatine supplementation may be further enhanced when it is consumed in conjunction with glycerol. ${ }^{47}$

The most recent study examining the effects of creatine supplementation in a hot, humid environment was conducted by Wright et al (2007)..$^{48}$ In this single-blinded study participants included 10 heat-acclimated, physically active men who completed the exercise protocol on two occasions within a 2 week period of time. During days 1-6 participants consumed $20 \mathrm{~g} / \mathrm{d}$ of placebo in four $5 \mathrm{~g}$ doses composed of sucrose and maltodextrin. During days 8-13 participants consumed the same drink with $5 \mathrm{~g}$ of creatine per serving. On days 7 and 14 participants completed the exercise session, which consisted of $6 \times 10 \mathrm{sec}$ maximal sprints on a cycle ergometer in heat $\left(35^{\circ} \mathrm{C}\right.$ and $60 \% \mathrm{RH}$ ) preceded by a $30 \mathrm{~min}$ cycling session at 100 Watts for 30 min to warm up muscles and induce a state of slight hypohydration. There were no significant differences between groups for markers of thermoregulation such as core temperature, sweat loss and relative change in plasma volume. However, markers of sprint performance, specifically peak power and mean power, were enhanced following creatine supplementation. ${ }^{48}$

\section{CONCLUSIONS}

Collectively, results from these studies suggest there is no reason to believe creatine enhances the risk of dehydration or muscle cramps. ${ }^{25} 33363745$ In fact, creatine supplementation may decrease the risk of dehydration during exercise by increasing total body water, ${ }^{35-37} 39454748$ lowering exercise core body temperature $e^{36} 39$ and reducing exercising heart rate and sweat rate. ${ }^{39}$ Creatine may also positively influence plasma volume during the onset of dehydration ${ }^{25}$ and enhance recovery, as the consumption of creatine during a $17 \mathrm{~h}$ recovery period following rapid weight loss of 4.5 to $5.3 \%$ of body mass significantly increased the ability to perform muscle work. ${ }^{49}$ Much research has been conducted highlighting the safety of creatine supplementation while exercising in hot and humid environments. Findings from these studies should be incorporated into future position statements regarding creatine supplementation as research does not support the claim that creatine supplementation may cause dehydration or muscle cramping. In fact, research suggests that creatine may lessen the risk of heat injury when exercising in hot and/or humid conditions by promoting a state of hyperhydration. For a review of pertinent studies see table 1 .

Competing interests: None declared.

\section{REFERENCES}

1. Feldman EB. Creatine: a dietary supplement and ergogenic aid. Nutr Rev 1999:57:45-50.

2. Fiske CH, Subbarow Y. Phosphocreatine. J Biol Chem 1929;81:629-79.

3. Hultman E, Bergstrom J, Anderson NM. Breakdown and resynthesis of phosphorylcreatine and adenosine triphosphate in connection with muscular work in man. Scand J Clin Lab Invest 1967;19:56-66.

4. Walker JB. Creatine: biosynthesis, regulation, and function. Adv Enzymol Relat Areas Mol Biol 1979;50:177-242.

5. Sipila I, Rapola J, Simell 0, et al. Supplementary creatine as a treatment for gyrate atrophy of the choroid and retina. N Engl J Med 1981;304:867-70.

6. Harris RC, Soderlund K, Hultman E. Elevation of creatine in resting and exercised muscle of normal subjects by creatine supplementation. Clin Sci (Lond) 1992;83:367-74.

7. Rawson ES, Volek JS. Effects of creatine supplementation and resistance training on muscle strength and weightlifting performance. J Strength Cond Res 2003;17:822-31.

8. Terjung RL, Clarkson P, Eichner ER, et al. American College of Sports Medicine roundtable. The physiological and health effects of oral creatine supplementation. Med Sci Sports Exerc 2000;32:706-17.

9. Poortmans JR, Francaux M. Adverse effects of creatine supplementation: fact or fiction? Sports Med 2000;30:155-70.

10. Haff GH, Kirksey BK, Stone MH. Creatine Supplementation. Strength and Conditioning Journal 1999;21:13-23.

11. Grande BM, Graves SB. Creatine supplementation: Forms, function, and effects. Strength and Conditioning Journal 2005;27:62-8.

12. Kreider RB, Melton C, Rasmussen CJ, et al. Long-term creatine supplementation does not significantly affect clinical markers of health in athletes. Mol Cell Biochem 2003;244:95-104.

13. Mayhew DL, Mayhew JL, Ware JS. Effects of long-term creatine supplementation on liver and kidney functions in American college football players. Int J Sport Nutr Exerc Metab 2002;12:453-60.

14. Persky AM, Brazeau GA. Clinical pharmacology of the dietary supplement creatine monohydrate. Pharmacol Rev 2001;53:161-76.

15. Pline KA, Smith CL. The effect of creatine intake on renal function. Ann Pharmacother 2005;39:1093-6.

16. Poortmans JR, Auquier H, Renaut V, et al. Effect of short-term creatine supplementation on renal responses in men. Eur J Appl Physiol Occup Physiol 1997;76:566-7.

17. Poortmans JR, Francaux M. Long-term oral creatine supplementation does not impair renal function in healthy athletes. Med Sci Sports Exerc 1999;31:1108-10.

18. Shao A, Hathcock JN. Risk assessment for creatine monohydrate. Regul Toxicol Pharmacol 2006;45:242-51.

19. Taes YE, Delanghe JR, Wuyts B, et al. Creatine supplementation does not affect kidney function in an animal model with pre-existing renal failure. Nephrol Dial Transplant 2003;18:258-64.

20. Bailes JE, Cantu RC, Day AL. The neurosurgeon in sport: awareness of the risks of heatstroke and dietary supplements. Neurosurgery 2002;51:283-6; discussion 286-8.

21. Greenwood M, Farris J, Kreider R, et al. Creatine supplementation patterns and perceived effects in select division I collegiate athletes. Clin J Sport Med 2000;10:191-4.

22. Greenwood M, Kreider RB, Greenwood L, et al. Cramping and Injury Incidence in Collegiate Football Players Are Reduced by Creatine Supplementation. J Athl Train 2003;38:216-19.

23. Juhn MS, O'Kane JW, Vinci DM. Oral creatine supplementation in male collegiate athletes: a survey of dosing habits and side effects. J Am Diet Assoc 1999;99:593-5. 
24. McGuine TA, Sullivan JC, Bernhardt DT. Creatine supplementation in high school football players. Clin J Sport Med 2001;11:247-53.

25. Watson G, Casa DJ, Fiala KA, et al. Creatine use and exercise heat tolerance in dehydrated men. J Athl Train 2006;41:18-29.

26. Congeni J, Miller S. Supplements and drugs used to enhance athletic performance. Pediatr Clin North Am 2002;49:435-61.

27. Pritchard NR, Kalra PA. Renal dysfunction accompanying oral creatine supplements. Lancet 1998;351:1252-3.

28. Alamada A, Mitchell T, Earnest C. Impact of chronic supplementation on serum enzyme concentrations. Federation of American Societies for Experimental Biology 1996:10:791.

29. Earnest CP, Almada AL, Mitchell TL. High-performance capillary electrophoresispure creatine monohydrate reduces blood lipids in men and women. Clin Sci (Lond) 1996;91:113-18.

30. Poortmans JR, Francaux M. Renal dysfunction accompanying oral creatine supplements. Lancet 1998; 352:234

31. Kraemer WJ, Volek JS. Creatine supplementation. Its role in human performance. Clin Sports Med 1999;18:651-66, ix.

32. Williams MH, Branch JD. Creatine supplementation and exercise performance: An update. Journal of American College of Nutrition 1998;17:216-34.

33. Powers ME, Arnold BL, Weltman AL, et al. Creatine Supplementation Increases Total Body Water Without Altering Fluid Distribution. J Athl Train 2003;38:44-50.

34. Silver MD. Use of ergogenic aids by athletes. J Am Acad Orthop Surg 2001; 9:61-70.

35. Ziegenfuss TN, Lowery LM., Lemon PWR. Acute fluid volume changes in men during three days of creatine supplementation. In: Journal of Exercise Physiology Online 1998. http://faculty.ass.edu/tboone2/asep/jan/3d.htm (accessed 14 Jan 2007)

36. Kern M, Podewils LJ, Vukovich M, et al. Physiological response to exercise in the heat following creatine supplementation. In: Journal of Exercise Physiology Online 2001:18-27. http://faculty.ass.edu/tboone2/asep/kem.pdf (accessed 7 Jan 2007)

37. Volek JS, Mazzetti SA, Farquhar WB, et al. Physiological responses to short-term exercise in the heat after creatine loading. Med Sci Sports Exerc 2001;33:1101-8.
38. Vogel R, Webster M, Erdmann L, et al. Creatine supplementation: Effect on supramaximal exercise performance at two levels of acute hypohydration. Journal of Strength and Conditioning Research 2000;14:214-19.

39. Kilduff LP, Georgiades E, James N, et al. The effects of creatine supplementation on cardiovascular, metabolic, and thermoregulatory responses during exercise in the heat in endurance-trained humans. Int J Sport Nutr Exerc Metab 2004;14:443-60.

40. Mendel R, Blegen M, Cheatham C, et al. Effects of creatine on thermoregulatory responses while exercising in the heat. Nutrition 2005;21:301-7.

41. Convertino VA, Keil LC, Bernauer EM, et al. Plasma volume, osmolality, vasopressin and renin activity during graded exercise in man. J Appl Physiol 1981;50:123-8.

42. Kraemer WJ, Armstrong LE, Hubbard RW, et al. Responses of plasma human atrial natriuretic factor to high intensity submaximal exercise in the heat. Eur J Appl Physiol Occup Physiol 1988;57:399-403.

43. Armstrong LE, Francesconi RP, Kraemer WJ, et al. Plasma cortisol, renin, and aldosterone during an intense heat acclimation program. Int J Sports Med 1989;10:38-42.

44. Rosene JM, Whitman SA, Fogarty TD. A Comparison of Thermoregulation With Creatine Supplementation Between the Sexes in a Thermoneutral Environment. J Athl Train 2004;39:50-5

45. Weiss BA, Powers ME. Creatine supplementation does not impair the thermoregulatory response during a bout of exercise in the heat. J Sports Med Phys Fitness 2006; 46:555-63.

46. Branch D, Schwarz W, Van Lunen B. Effect of creatine supplementation on cycle ergometer exercise in a hyperthermic environment. Journal of Strength and Conditioning Research 2007;21:57-61.

47. Easton C. Turner S, Pitsiladis YP. Creatine and glycerol hyperhydration in trained subjects before exercise in the heat. Int J Sport Nutr Exerc Metab 2007;17:70-91.

48. Wright GA, Grandjean PW, Pascoe DD. The effects of creatine loading on thermoregulation and intermittent sprint exercise performance in a hot humid environment. J Strength Cond Res 2007;21:655-60.

49. Oopik V, Paasuke M, Timpmann S, et al. Effects of creatine supplementation during recovery from rapid body mass reduction on metabolism and muscle performance capacity in well-trained wrestlers. J Sports Med Phys Fitness 2002;42:330-9.

\section{3rd International Football Medicine Conference}

19-21 February 2010, Sun City, South Africa

This meeting, taking place prior to the 2010 FIFA World Cup South Africa, will provide an update on the current evidence in football medicine. The main topic areas reflect the key questions to be discussed in football medicine:

- preventive medicine in football

- football under extreme conditions

- advances in diagnosis and treatment of injuries and medical conditions

- new strategies in the fight against doping

- football for health.

Workshops will also be held on topics such as pre-competition medical assessment, cardiac assessment, doping control and age determination by MRI, etc. You are invited to submit an abstract related to original research in football medicine for consideration as a poster or oral presentation as free submissions.

Further details: http://www.fifa.com/medical 


\section{BJSM}

\section{Putting to rest the myth of creatine supplementation leading to muscle cramps and dehydration}

V J Dalbo, M D Roberts, J R Stout, et al.

Br J Sports Med 2008 42: 567-573 originally published online January 9, 2008

doi: 10.1136/bjsm.2007.042473

Updated information and services can be found at:

http://bjsm.bmj.com/content/42/7/567.full.html

These include:

References This article cites 47 articles, 7 of which can be accessed free at: http://bjsm.bmj.com/content/42/7/567.full.html\#ref-list-1

Email alerting Receive free email alerts when new articles cite this article. Sign up in service the box at the top right corner of the online article.

Notes

To request permissions go to:

http://group.bmj.com/group/rights-licensing/permissions

To order reprints go to:

http://journals.bmj.com/cgi/reprintform

To subscribe to BMJ go to:

http://group.bmj.com/subscribe/ 